\title{
Editorial
}

\section{Contemporary Archaeology and Anti-Racism: A Manifesto from the European Society of Black and Allied Archaeologists}

\author{
Peggy Brunache $^{1,2}$, Benjamina Efua Dadzie ${ }^{3}$, Karen Goodlett ${ }^{4}$, \\ Laura Hampden $^{5}$, Amal Khreisheh ${ }^{6}$, Chioma Vivian Ngonadi ${ }^{7}$, \\ Danika Parikh $^{8}$ and Jeannette Plummer Sires 9 \\ ${ }^{1}$ Authorship is alphabetical and equally shared among all authors \\ ${ }^{2}$ Beniba Centre for Slavery Studies, University of Glasgow, UK \\ [peggy.brunache@glasgow.ac.uk] \\ ${ }^{3}$ Museum of Archaeology and Anthropology, University of Cambridge, UK \\ [bed26@cam.ac.uk] \\ ${ }^{4}$ University of Southampton, UK [kr2n19@soton.ac.uk] \\ ${ }^{5}$ Historic England, London, UK \\ ${ }^{6}$ South West Heritage Trust, Taunton, UK [amal.khreisheh@swheritage.org.uk] \\ ${ }^{7}$ Department of Archaeology, University of Cambridge, UK \\ ${ }^{8}$ University of Cambridge Museums, UK [dp375@cam.ac.uk] \\ ${ }^{9}$ The British Museum, London, UK [jplummersires@britishmuseum.org]
}

The European Society of Black and Allied Archaeologists (ESBAA) is a collective of anti-racist archaeologists from across Europe, West and Southern Africa, the Middle East, South Asia, and North America. ESBAA was founded and is led by women of colour. We recognize and acknowledge that archaeology is full of long-standing racist and violent histories, and our goal is to address this issue and to work towards social and economic equality. We are committed to the decolonization of archaeological knowledge, ethics, behaviour, and practice. In our work, we create equitable spaces for academic engagement, interdisciplinary and transnational collaboration, and mentorship for early career archaeologists. Our strength as an organization lies in the breadth of experiences of our members and their commitment to developing strong interdisciplinary archaeological networks. Members work across all parts of the discipline and include academics, students, museum professionals, historic environment officers and commercial archaeologists. We have close links with other sector support groups including Museum Detox and the Society of Black Archaeologists (2020, 2021; Franklin et al., 2020; Flewellen et al., 2021).

Although the intersectional obstacles archaeologists of colour face in this sector are multifaceted, we have identified a set of fundamental barriers that have a profound 
impact on the ability to access the profession and enjoy a fruitful career progression. These issues form the core of our manifesto but are not exhaustive. This list should be seen as a first step in raising awareness, alongside necessary preliminary practices to effect radical profession-wide structural and systemic change.

\section{Access AND Recruitment}

Archaeology in Europe has yet to successfully address the underrepresentation of archaeologists of colour. Archaeology has almost exclusively consisted of a specific and narrow demographic. In the UK this is evidenced in the Profiling the Profession report of 2012-2013, which found that 99 per cent of working archaeologists were white (Aitchison \& RocksMacqueen, 2013: 98). This lack of diversity clearly affects how the archaeological record is interpreted, and by whom. It culminates in positioning predominantly white archaeologists as the gatekeepers of heritage and knowledge, which leads to a self-perpetuating echo chamber. Unrepresented voices can counter monocultural narratives, and offer different perspectives that enrich and augment the archaeological record (Dave, 2016).

Recruitment practices often operate in ways that are opaque to those outside the sector, testing whether an applicant is familiar with the recruitment process rather than their potential to succeed in a given role. Archaeological roles are traditionally advertised on sector-specific and/or membership-led recruitment sites that may be unfamiliar to those not already within the sector. This is problematic, as aspiring archaeologists of colour are less likely to have developed contacts within the sector who can provide the insider knowledge required for success. There is a tendency for archaeological employers to recruit in their own image, further replicating the predominantly white workforce. There is a lack of paid training opportunities and true entry-level roles. Traditionally there has been an expectation that people will gain the experience needed through volunteering. This disproportionately disadvantages archaeologists of colour, who are either more likely to lack the financial resources that make volunteering a possibility or less likely to be accepted on volunteer programmes. Pay for archaeological roles is low in comparison to similarly skilled roles in other sectors, job security is poor, and working hours offer less flexibility, further disadvantaging potential archaeologists of colour.

\section{RETENTION AND SuPPorT}

Institutions and companies looking to improve the racial diversity of their staff should not regard hiring underrepresented professionals as the end of their responsibility towards workplace equity. As a sector that is entrenched in colonial practices, archaeology shows an egregious lack of awareness and empathy regarding the challenges faced by archaeologists of colour working in these environments. These include: isolation; widespread unawareness of cultural practices; racist comments or a hostile workplace; management and HR who are unequipped to deal with these situations; and a focus on preserving 'team spirit' and the status quo. Archaeologists of colour may be faced with the choice to make a complaint, which is then viewed as rocking the boat and subsequently mishandled by untrained management, or to stay silent at the cost of their 
dignity in the workplace. All of these outcomes affect mental health and emotional wellbeing, and none of them encourage retention. This lack of peer and structural support leaves these staff members without the tools necessary to thrive in their careers. There should be a conscientious effort by institutions and companies to move towards more equitable and ethical practices with regard to hiring, job retention, and progression.

\section{Mentoring ANd Allyship}

The structures of inequity underpinned by white supremacy and patriarchy often lead to (potential) archaeologists of colour feeling marginalized with little to no formal or informal support in navigating the rough waters for career ascension. The burden of responsibility is placed on people of colour to call out racial discrimination (direct and indirect, overt and covert). Continuous exposure to discrimination with no investment in repair can push us out of the profession, especially in the early career stage. Isolation, silencing, gaslighting, victimization, and microaggressions can lead to CTSD (continued traumatic stress disorder). Moreover, these forms of social violence can operate as modes of oppression that silence those working to challenge the structures that maintain the privilege of a few members of our discipline.

Allyship, mentoring, and reverse mentoring partnerships are one way to prevent the loss of diverse voices from the profession, address the lack of support, and aid career progression. Allyship relies on the voices of those in the majority undertaking the work to understand where their power lies to affect change, and to relieve the burden of responsibility from the oppressed. Mentoring offers a chance for established archaeologists to provide support, professional training, and networks for emerging archaeologists of colour. Reverse mentoring, vertical and horizontal mentorship partnerships that focus on learning, anti-racism, skills, and knowledge sharing can increase opportunities and success across all employment levels.

\section{ESBAA Vision AND Mission}

Having identified these barriers and more, ESBAA acknowledges and addresses the long-standing racist and violent histories within archaeology; we work to create equitable and safe spaces for archaeologists of the present and future.

Our mission is to support the profession and the organizations/institutions within it to build and sustain frameworks that foster safe and supportive spaces for archaeologists of colour to thrive. We are a growing network of anti-racist archaeologists who will work with like-minded individuals and organizations to increase the visibility of archaeologists of colour, promote their achievements, and improve representation across the profession. We seek to improve our field and develop more equitable conditions in archaeology by addressing practice and behaviour that perpetuates structural inequality, working towards decolonization, increasing opportunities for archaeologists of colour, creating restorative spaces for archaeologists of colour, sharing resources, and fostering collaboration, allyship, and mentoring. 


\section{Call to Action}

The discipline of archaeology is rooted in the colonial project that has privileged white, cis male, able bodied, upper and middle class scholars. Despite this, our contemporary discipline comprises people of different backgrounds and ethnicities. However, this diversity has not led to inclusivity because these ideals continue to have a profound influence on what is deemed to be or to look professional. Therefore, we make this call to action to place focus on our methodologies, practices, pedagogies, and collaborations with the understanding that they must be underpinned by an anti-racist stance:

- Understand that activism is not performative, it is grounded in changing the structures of inequity and racism.

- Get comfortable engaging in uncomfortable conversations.

- Bear witness when you see a racist incident. This is part of the ethics of archaeological practice. Don't sit silently by. Acknowledge the incident and intervene where it does not escalate the situation in a way that will be damaging to the archaeologist of colour.

- Learn how to take feedback with grace and accept that there is much to learn. When an archaeologist of colour feels safe enough to provide feedback, take the time to listen actively and consider your response. Tone policing, such as by countering with accusations of rudeness, meanness, loudness, or unprofessionalism, is damaging. Rejection or knee-jerk denials act to preserve systems of oppression. Challenge yourself to accept feedback with grace and embrace the learning process. Resist the urge to centre yourself as the victim of a personal attack. Instead, truly engage with the substance of what you're being challenged to consider.

Applying decolonization practices to our discipline and our thinking is a long-term project. We invite all of those who share our vision to join us in our efforts in creating a more equitable profession, rich in a multiplicity of voices. The future of archaeology is in all of our hands.

\section{REFERENCES}

Aitchison, K. \& Rocks-Macqueen, D. 2013. Archaeology Labour Market Intelligence: Profiling the Profession 2012-2013. Landward Research Limited.

Dave, R. 2016. Archaeology Must Open up to Become More Diverse. The Guardian. https:// www.theguardian.com/culture-professionals-network/2016/may/23/archaeology-must-open-upbecome-more-diverse

Flewellen, A., Dunnavant, J., Odewale, A., Jones, A., Wolde-Michael, T., Crossland, Z. \& Franklin, M. 2021. 'The Future of Archaeology Is Antiracist': Archaeology in the Time of Black Lives Matter. American Antiquity, 86: 224-43. https:/www.doi.org/10.1017/aaq.2021.18

Franklin, M., Dunnavant, J., Flewellen, A. \& Odewale, A. 2020. The Future is Now: Archaeology and the Eradication of Anti-Blackness. International Journal of Historical Archaeology, 24: 753-66. https://doi.org/10.1007/s10761-020-00577-1

Society of Black Archaeologists, Theoretical Archaeology Group (North America), and the Columbia Centre for Archaeology 2020. "Archaeology in the Time of Black Lives Matter" Resources List. [online] [accessed 10 May 2021]. Available at: <https://static1.squarespace. $\mathrm{com} / \mathrm{static} / 5 \mathrm{ba} 9378 \mathrm{ebfba3e} 7 \mathrm{~b} 319 \mathrm{e} 2 \mathrm{ce} 6 / \mathrm{t} / 5$ f2f05c509e14e53cb898607/1596917190138/ Compilation+of+Resources+SBA+2020.pdf> 
Society of Black Archaeologists 2021. Building a Foundation for Action: Anti-Racist Historic Preservation Resources. [online] [accessed 10 May 2021]. Available at: <https://docs.google. com/document/d/1IqERcowdaMnHQpgnA9PfPdEabG16xYexJA2fLOzwtCs/>

\section{FURTHER READING}

Atalay, S. 2006. Indigenous Archaeology as Decolonizing Practice. American Indian Quarterly, 30: 280-310. https://doi.org/10.1353/aiq.2006.0015

Battle-Baptiste, W. 2011. Black Feminist Archaeology. London: Routledge. https://doi.org/10. 4324/9781315096254

HEPI 2020. New Report Calls for the Decolonisation of Universities in Order Address a 'Silent Crisis'. [online] [accessed 10 May 2021]. Available at: <https://www.hepi.ac.uk/2020/07/23/ new-report-calls-for-decolonisation-of-universities-in-order-address-the-silent-crisis-inuniversities/>

Liebmann, M. \& Rizvi, U.Z. eds. 2008. Archaeology and the Postcolonial Critique. Lanham (MD): Rowman and Littlefield.

Smith, L.T. 2021. Decolonizing Methodologies: Research and Indigenous Peoples. London: Zed Books. https://doi.org/10.5040/9781350225282

White, W. \& Draycott, C. 2020. Why the Whiteness of Archaeology is a Problem. Sapiens, 7 July. [online] [accessed 10 May 2021]. Available at: <https://www.sapiens.org/archaeology/ archaeology-diversity/>

White-Lewis, D.K. 2020. The Facade of Fit in Faculty Search Processes. The Journal of Higher Education, 91: 833-57. https://doi.org/10.1080/00221546.2020.1775058

Women's Classical Committee UK 2017. How to Avoid a Manel and Beyond. [online] [accessed 10 May 2021]. Available at: <https://wcc-uk.blogs.sas.ac.uk/files/2017/10/WCC-UK-DiversityGuidance-2018.pdf> 